\title{
O Novo Paradigma da Segurança na África: a Estratégia Securitária Regional Angolana
}

\author{
The New Security Paradigm in Africa: \\ the Angolan Regional Strategy
}

"A condução da nossa política externa continuou a pautar-se por uma actuação objectiva em actos e eventos conducentes à consolidação do entendimento e cooperação entre as nações e à preservação da paz, da estabilidade e da segurança internacionais. [...] Nós continuaremos a cumprir as nossas obrigações e a assumir as nossas responsabilidades no plano internacional, em especial no que diz respeito a África no seu todo e em particular no quadro dos conjuntos económicos e políticos a que pertencemos, como a SADC e a CEEAC"

José Eduardo dos Santos, Cerimónia de Abertura da IV Sessão Legislativa da II Legislatura da Assembleia Nacional, Luanda, 18 de Outubro de 2011

\section{INTRODUÇÃO}

Assiste-se atualmente a uma tendência global para a criação de associações de países alinhados em estratégias concertadas de autodefesa e de apoio ao desenvolvimento sustentado. Estas alianças regionais e regionalizadas permitem alavancar parte dos objetivos nacionais que, para os Estados, são difíceis, senão impossíveis de almejar numa perspectiva isolacionista e desarticulada. Estas convergências político-estratégicas conjunturais obrigam à partilha de interesses, espaços, objetivos, da própria soberania e do assumir de responsabilidades políticas e estratégicas, pois

\footnotetext{
* Doutor em Relações Internacionais (Universidade de Lisboa). Investigador no Centro de Estudos Internacionais do Instituto Universitário de Lisboa (CEI-IUL) e do CINAMIL/Academia MIlitar em Portugal. E-mail: bernardino.lmb@hotmail.com.
} 
que as ameaças e os desafios globais requerem atualmente soluções e respostas melhor articuladas e crescentemente mais organizadas e robustas.

$\mathrm{Na}$ África, essa tendência parece estar associada ao surgimento das Organizações Regionais Africanas, nomeadamente, com a criação em 1963 da Organização de Unidade Africana (OUA) e, mais recentemente, em meados de 2000, com a transformação para a União Africana (UA). Ao nível subsaariano, principalmente com a criação, em 1981, da Comunidade Econômica dos Estados da África Central (CEEAC) e, em 1992, da Comunidade para o Desenvolvimento da África Austral (SADC), passou a existir um sistema regional securitário inovador, em que estas organizações passaram a ser consideradas, nos seus espaços de interesse conjuntural permanente, os atores determinantes na integração econômica e securitária da região subsaariana e na África (Almeida, 2011 ).

No entanto, estas organizações regionais enfrentaram, ao longo da sua história recente, alguns desafios em termos de integração, crescimento institucional e de alinhamento político-estratégico, constatando-se a existência de diferentes concepções de estabilidade política, de governança e até de democratização, entre os seus países-membros, o que não contribuiu para uma efetiva operacionalização e uma adequada concertação políticoestratégica regional (Bernardino, 2013).

Este novo quadro geopolítico inovador levou os Estados e as organizações africanas a conferirem maior relevância ao fator segurança, pois, sem paz e estabilidade político-social, não existem condições para um desenvolvimento sustentado e também não existe desenvolvimento sustentado sem uma segurança sustentada e, cada vez mais, partilhada coletiva ou cooperativamente. Neste contexto, foi desenhada a partir de 2003 a designada Arquitetura de Paz e Segurança Africana (APSA), no intuito de contribuir, coletivamente, para melhorar o índice de segurança regional, constituindo-se num mecanismo potencialmente gerador de paz e segurança, onde os atores globais e, principalmente, os regionais assumem um papel estratégico na sua dinamização político-estratégica e na efetiva operacionalização tático-operacional. Aspeto que a República de Angola tem vindo a dedicar maior atenção, e que tendencialmente irá tornar-se mais relevante e estratégica no atual contexto de afirmação da sua política externa regional e no desenvolvimento das Forças Armadas Angolanas (FAA).

A política de defesa nacional angolana aposta no desenvolvimento do setor da segurança e de defesa do Estado, que alavancado no crescimento econômico e na estratégia de afirmação regional, assenta na capacitação 
do instrumento militar e nas orientações estratégicas para que as Forças Armadas façam parte dos mecanismos proativos de cooperação regional, permitindo-lhes contribuir para a afirmação de Angola na região e na África. Neste âmbito, a interdependência entre os fatores de afirmação, como é o controle da soberania transfronteiriça e as contribuições para a segurança nos países vizinhos, concorrem também para reforçar a segurança e estabilidade interna, pois, como refere Malaquias (2011), a procura de soluções para os problemas internos de Angola é feita também através da participação nas dinâmicas regionais.

Igualmente, a partilha do esforço estratégico no âmbito da segurança faz-se, multilateralmente, através da participação nas ORA, e, mais concretamente, no âmbito da APSA, onde os exercícios militares conjuntos anuais constituem um dos mecanismos por excelência da partilha de experiências e de interoperabilidade do vetor militar. Integrado nesta dinâmica, os exercícios conjuntos e combinados Dolphin e Zambeze Azul, no contexto da SADC, e Kwanza, no âmbito da CEEA, constituem dois bons exemplos do supracitado. Aspetos que procuramos interligar e analisar neste ensaio, abordando a participação das FAA nestes exercícios militares que se realizam em Angola no passado rente e que a projetam como potência regional securitária em ascensão - fato que, numa conjuntura e num quadro em que é membro não-permanente do Conselho de Segurança das Nações Unidas, lhe imputa maior responsabilidade como agente da segurança regional e global.

A metodologia de investigação científica empregue, de raiz hipotéticodedutiva, assenta necessariamente numa pesquisa bibliográfica, mas está consolidada pela participação do autor em projetos de Cooperação Técnico-Militar (CTM) ao serviço das Forças Armadas Portuguesas em Angola, que permitiu um contato com as altas patentes das FAA e, assim, construir um racional para o objetivo que nos propomos desenvolver neste ensaio que é analisar, em face do inovador paradigma regional securitário africano atual, saber qual é a estratégia de Angola e como podem as Forças Armadas constituírem mecanismo da ação estratégica do Estado angolano.

\section{A PERSPECTIVA ANGOLANA DA SEGURANÇA E DEFESA: A INSERÇÃO NOS ESPAÇOS REGIONAIS DE DEFESA}

A criação de um exército único e as atribulações político-militares que se seguiram às eleições de 1992 dificultaram a materialização do precei- 
tuado em meados de 1991 nos Acordos de Bicesse, ao abrigo do qual as então forças contendoras ${ }^{1}$, se fundiriam num Exército Nacional único, cuja não materialização conduziu o país a um dos mais difíceis períodos da sua história recente.

A assinatura, em 4 de Abril de 2002, do Memorando de Entendimento de Luena viria a marcar o fim da guerra fratricida em Angola, passando-se a definir novos rumos na edificação do país e na construção da paz, tendo contribuído para reforçar as capacidades e o espírito de corpo das FAA, cuja missão passou a estar constitucionalmente estabelecida, nos termos do Art. $^{\circ} 207^{\circ}$ n. ${ }^{\circ} 1$ da Constituição da República de Angola e replicada na Lei 2/93 de 26 de Março, a Lei de Defesa Nacional e das Forças Armadas, atualmente em revisão (Leão e Rupiya, 2005) (Júnior, 2003).

Este enquadramento serviu para reforçar a noção que em Angola a segurança e a estabilidade estão dependentes atualmente da existência de uma multiplicidade de ameaças e riscos não convencionais, transnacionais e persistentes, que constituem ameaças tangíveis à segurança nacional e regional. Ao nível internacional, trata-se de fenômenos de criminalidade organizada, terrorismo, fundamentalismo político-religioso, da problemática da proliferação de armamento e dos riscos ambientais, catástrofes humanitárias e pandemias que ameaçam a vida de milhões de seres humanos, nomeadamente na África. Ao nível estatal, trata-se do aparecimento de Estados falhados e da multiplicação de conflitos violentos e de guerras civis, que se tornaram fenômenos correntes, representando, direta e indiretamente, uma ameaça à segurança e estabilidade regional. Como exemplo recente, há o caso da Guiné-Bissau, que envolveu diretamente o Estado angolano e as FAA através da criação da Missão de Segurança das Forças Angolanas na Guiné-Bissau (MISSANG-GB), no intuito de contribuir para a RSS e RSD neste país e, mais recentemente, a relação com a República Centro Africana e a sempre problemática República Democrática do Congo.

Neste contexto, o conceito de segurança parece registar duas alterações fundamentais. Primeiro, a segurança não se centra exclusivamente na segurança clássica do Estado, pois significa, também, a segurança humana. E, em segundo lugar, contra riscos, ameaças e conflitos transnacionais, a resposta terá que basear-se, essencialmente, na cooperação regional ou internacional, pois será num quadro de segurança cooperativa e coletiva, que se procurará colmatar as debilidades dos Estados.

Assim, para fazer face ao atual cenário da segurança internacional, em 
que as políticas de defesa nacional e os instrumentos de segurança e defesa terão que desenvolver respostas mais adequadas, em que a defesa nacional deve ter como objetivos fundamentais não só a competência para garantir a segurança do Estado e dos cidadãos, mas também a capacidade para projetar segurança no plano externo e reforçar a cooperação no quadro dos sistemas de alianças conjunturais, em favor da segurança e da paz interna e regional.

Constituem objetivos atuais da Política de Defesa Nacional de Angola:

garantir a soberania do Estado, a independência nacional, a integridade do território e os valores fundamentais da ordem constitucional; garantir a liberdade e a segurança das populações e do património nacional; garantir a liberdade de acção dos órgãos de soberania, o regular funcionamento das instituições democráticas e a realização das funções e tarefas essenciais do Estado[...],

como podemos constatar na norma constitucional do Artigo $207^{\circ}$ da Constituição da República de Angola (Angola, 2010). Pois que o atual contexto de segurança internacional e a resposta adequada da Política de Defesa Nacional apontam, como vimos, para uma concepção mais alargada e partilhada da segurança e ainda a adopção de uma estratégia mais integrada e multidimensional nas Políticas de Defesa, com reflexos na doutrina estratégica e operacional, na definição das estruturas de comando e controle e, consequentemente, nas missões das Forças Armadas.

No âmbito legislativo, para além das missões tradicionais, as FAA são incumbidas de participar de missões internacionais, nomeadamente nos sistemas de defesa coletiva, e no futuro, tenderão à participação em missões de apoio à política externa, designadamente, através da integração em estruturas de gestão de crises, nas missões de natureza humanitária e operações de manutenção da paz, no quadro das organizações de que Angola é Estado-membro e a vertente mais africanista da Comunidade dos Países de Língua Portuguesa (CPLP).

As FAA, constitucionalmente, assumem as suas responsabilidades legais primárias nas missões de luta contra agressões e ameaças transnacionais, nos termos da lei e em coordenação com os instrumentos internos, nomeadamente: as forças e serviços de segurança e sistemas de informação estratégica, executando, entre outras, missões de interesse público; missões residuais de busca e salvamento; de fiscalização marítima e de apoio às populações, especialmente na desminagem; no apoio ao abastecimento público e em situação de catástrofes naturais e pandemias; atuando de for- 
ma supletiva e complementar da proteção civil angolana, pois estão empenhadas nos programas de proteção (gestão de crises) e de segurança com os países membros das organizações regionais a que pertencem.

Para adaptar as Forças Armadas aos novos tempos e aos inovadores desafios transnacionais, a Política de Defesa Nacional Angolana vem definindo como vetores de intervenção estratégica a intercessão militar regional, criando, para o efeito, as seguintes linhas de ação, com vistas à modernização, operacionalização e inserção das Forças Armadas Angolanas no contexto regional:

- Consolidar e sustentar um modelo de profissionalização das Forças Armadas, garantindo a sustentabilidade baseada em recursos humanos profissionais e qualificados, procurando que a experiência operacional se apresente apelativa e que contribua para a operacionalidade das FAA;

- Modernizar os equipamentos e as infraestruturas no intuito de contribuir para a interoperabilidade, adequando-se às novas missões, necessidades e exigências; nomeadamente, através da presença em missões militares internacionais. Nesse sentido, constitui-se como prioridade a revisão do Conceito Estratégico de Defesa Nacional (CEDN) e da Lei de Defesa Nacional e das Forças Armadas, apontando para uma maior intervenção regional no contexto das ORA e das Organizações Internacionais;

- Efetivar e fomentar a Reestruturação da Estrutura Superior da Defesa Nacional, concretizando a reforma da legislação na área da defesa, nomeadamente, as Leis de Bases das Forças Armadas e o Estatuto dos Militares das Forças Armadas, concorrendo para a valorização da condição militar e contribuindo para a desejada profissionalização das FAA;

- Dignificar a função militar, reconhecendo e valorizando a profissão militar no quadro das funções do Estado e incentivando (financeiramente, prestígio e valorização para a função e para a carreia) a participação nas missões de Forças Armadas Angolanas Destacadas;

- Garantir a sustentação do orçamento da defesa nacional no sentido de definir uma política orçamental que assegure um investimento sustentado na área da defesa e das FFAA, com vistas ao cumprimento dos compromissos internacionais do Estado; 
RBED, v. 2, no 1, jan./jun. 2015

- Desenvolver táticas, técnicas e procedimentos, integrando doutrinas consentâneas com os contextos regionais de inserção militar, nomeadamente, no quadro das missões de operações de paz, ajuda humanitária e nas operações de resposta a crises;

- Ocupar os cargos militares nas estruturas das ORA, permitindo interagir e acompanhar os desenvolvimentos em matéria de segurança e defesa regional;

- Apostar na formação de quadros e capacitá-los para desenvolverem funções de Estado-Maior e de observador ou assessor militar nas alianças regionais de defesa ou no quadro das Nações Unidas.

A defesa nacional visa a proteção dos cidadãos nacionais dentro e fora do espaço territorial nacional e contribui para a segurança, desenvolvimento e bem-estar das populações, o que implica apostar numa maior credibilidade e ação, da sua componente militar, às suas Forças Armadas. Como política transversal que é, a defesa nacional deve, assim, ter um caráter abrangente e permanente, exercendo-se em todo o tempo e em qualquer lugar onde exista interesses do Estado a proteger, integrando componentes militares e não militares, numa sinergia única em prol do Estado e da nação.

Assim sendo, no plano interno, as FAA participam, crescentemente, no cumprimento de missões de interesse público, atuando mais perto dos cidadãos, pois que, aproveitando as suas capacidades, acrescenta valor à sua presença ao longo do território e promove, também por essa via, uma relação mais estreita e mutuamente enriquecedora com as populações. As Forças Armadas, como instrumento ativo da política, contribuem de forma significativa para aumentar o potencial de governança do Estado, constituindo um dos vetores principais da sua política externa, um fator de dissuasão face a eventuais agressões ou ameaças externas ao espaço aéreo e marítimo de Angola, bem como na salvaguarda das linhas de comunicação internacionais que cruzam o espaço soberano angolano.

\section{CONTRIBUIÇÕES DE ANGOLA PARA A PAZ E SEGURANÇA REGIONAL}

Na sequência do disposto na Carta das Nações Unidas, Art..$^{\circ} 23^{\circ}$ n. ${ }^{\circ}$ 1, o Conselho de Segurança é o organismo responsável pela paz e segurança mundial, e forja as parcerias estratégicas conjunturais necessárias com outras organizações internacionais e regionais para operacionalizar esse 
desiderato no globo. Neste contexto, Angola, ao assumir em 2015 como membro não-permanente do Conselho de Segurança das Nações Unidas, vê-se na obrigatoriedade moral de contribuir e pensar a segurança como ator global. Aspecto que se pode traduzir num incremento de atividades e participações ao nível das missões de paz das Nações Unidas, prioritariamente na África, mas também um pouco por todo o mundo.

Segundo este paradigma, e tendo como objetivo primário promover a estabilidade e o progresso na África, os chefes de Estado e de governo africanos aprovaram o estabelecimento da APSA, definindo, no protocolo relativo à edificação do Conselho de Paz e Segurança da UA, a utilidade e perspectiva de atuação como mecanismo criado para a prevenção, gestão e resolução de conflitos, agindo regionalmente para a promoção da paz, da segurança e estabilidade no continente. Assim, constituiu-se, para além do Conselho de Paz e Segurança, a Força Africana em Alerta (FAeA), o Sistema de Alerta Continental ${ }^{2}$, o Painel de Sábios e o Fundo para a Paz, como os principais pilares da estratégia de segurança coletiva africana (Cillier, 2005).

No quadro deste mecanismo, a estrutura operacional para a participação em operações de paz é a FAeA, constituída por cinco brigadas regionais, compostas pelas componentes militar ${ }^{3}$, policial e civil, na base de uma unidade por cada região. O Documento Quadro da Edificação da FAeA (2012) orienta a sua prontidão, pretendendo obter as capacidades para cumprir missões de acordo com um eventual mandato da ONU, da UA ou das OR, em prol da segurança regional.

As FAA existem para garantir a defesa dos interesses nacionais, mas participam, quando necessário e definido politicamente pelo Executivo, em campanhas militares para além das suas fronteiras, fato que, aliado à forma como procuraram contribuir para a resolução dos conflitos internos em Guiné-Bissau, República Democrática do Congo e na Costa do Marfim, permitiu-lhes granjear algum prestígio regional e internacional. Prestígio que importa manter e consolidar, nomeadamente, através da continuada participação nos mecanismos de estabelecimento da paz e segurança regional que Angola subscreveu, até porque as intervenções ad-hoc têm um impacto político e estratégico regional muito menor e, quantas vezes, negativo para as Forças Armadas e especialmente para o Estado.

A República de Angola, na qualidade de Estado-membro da UA e inserida nas comunidades econômicas regionais, assumiu a obrigação de participar com um batalhão na FAeA e, ainda, no âmbito dos compromissos com 
a CEEAC, Angola ficou responsável pela criação de um Centro de Excelência de Operações de Paz, de nível tático, que pode projetar Angola e as suas Forças Armadas no contexto africano como produtor de segurança regional. Quanto à preparação das forças, constata-se que as FAA têm feito parte dos efetivos que integram estes compromissos regionais, operando com base na doutrina (possível) da ONU (e da UA), visando a integração e emprego no quadro das FAeA regionais, o que implica também ter uma doutrina nacional consolidada e a realização de treinos e exercícios operacionais onde permita criar e desenvolver as capacidades para emprego conjunto de uma força-tarefa africana no contexto regional. Aspeto que Angola e as suas FA têm desenvolvido na vertente regional.

Entretanto, para operacionalizar este desiderato, as FAA formaram dois núcleos para formação na área das operações de paz. Um de nível estratégico-operacional, que funciona na Escola Superior de Guerra - o Núcleo Estratégico-Operacional -, e outro de nível tático, a funcionar no Centro de Instrução de Operações de Paz (CIOP), adstrito à Brigada de Forças Especiais, na região de Cabo Ledo, unidade geradora de forças para as missões de paz, tendo, já preparado para empregar, um núcleo de observadores militares e um batalhão de infantaria - que iniciou em 2010 a fase de preparação táctica e que viria a ser projetado para, Guiné-Bissau em 2011 e, atualmente (2014/2015), eventualmente forças para a RDC e para a Força de Reação Rápida da UA.

O Centro de Instrução das Forças Especiais das Forças Armadas Angolanas, colocalizado com o Centro de Instrução de Operações de Apoio à Paz, salienta ainda que as operações de paz, dadas as suas especificidades, multiplicidades de cenários e caráteres multinacionais, são operações de grande complexidade que requerem forças empenhadas, flexíveis, aptidão para responderem aos vários cenários, e exige dos efetivos das FAA um bom nível de preparação técnico-táctica, além de um estado moral e psicológico elevado, que só se consegue com muito treino.

Mais recentemente, as estruturas do CIOP, junto da Escola Superior de Guerra no Núcleo Estratégico Operacional, continuam a funcionar. Entretanto, foi reforçada com maior número de instrutores em virtude desses terem sido colocados na ESG, em detrimento da sua anterior colocação junto da $1^{\text {a }}$ Brigada de Infantaria Motorizada em Vale Paraíso. Esta mudança provou a desativação momentânea do núcleo tático que existia naquela unidade, estando a sua reativação prevista para breve. O CIOP dá continuidade à sua missão de ministrar instrução na área das operações de paz 
às unidades, militares ou civis, nacionais ou estrangeiras, bem como aos contingentes de forças que integram a MISSANG-GB (Bernardino, 2013).

Em 2011, foi criada, na Direção de Operações do EMGFAA, uma unidade orgânica vocacionada para as operações de apoio à paz, com o objetivo de criar uma estrutura nova para o CIOP e o respectivo quadro orgânico, com ligação funcional à nova unidade orgânica, ficando definidas as duas áreas fundamentais das operações de paz: a operacional e a da formação (incluindo o treino). Neste sentido, os trabalhos mais recentes têm evoluído já de acordo com o novo modelo, em especial, a coordenação com a nova unidade de OAP/EMGFAA, como é o caso da preparação de forças para integrarem a MISSANG-GB.

Derivado desta evolução, o CIOP passará a ter dependência hierárquica do Chefe de Estado-Maior-General, tendo uma dependência funcional da Direção de Operações e mantendo a dependência técnica da Direção Principal de Preparação de Tropas e Ensin. Na sequência, e porque as FAA sentiram a necessidade da existência de um órgão responsável pela formação em estreita ligação com a parte operacional, elaboraram-se estudos sobre a possível futura localização do CIOP, ou um órgão semelhante com outra designação.

Segundo os parâmetros estratégicos da UA e, após um período em que Angola se dedicou a consolidar a paz interna, a reconstruir o país e a adaptar as estruturas de defesa e segurança, passou a desenvolver a sua presença nas organizações regionais através da participação em treinos operacionais no contexto das operações de paz, no quadro da ONU e/ou da UA, possibilitando que os militares e policiais possam integrar, em curto prazo, as missões de paz na África. Contudo, na atual dinâmica securitária africana e na região, implica em nossa opinião, por parte de Angola, uma maior proatividade e pragmatismo, pois que a presença de Angola nas ORA passará, no futuro, também por uma maior intervenção militar no âmbito da política externa de defesa. Isto parece apontar para uma participação crescente no contexto regional subsaariano e uma maior relevância das FAA no quadro da APSA ${ }^{4}$.

Quanto aos exercícios da FAeA, o protocolo do sistema COPAX (CEEAC), no artigo $14^{\circ}$, atribui ao Conselho de Ministros da Comissão de Defesa e Segurança da UA a competência para a organização, planificação e avaliação dos exercícios militares regionais, como resposta às necessidades do desenvolvimento das capacidades da Força Multinacional da África Central em matéria de operações de manutenção da paz, apoiadas nos 
fundamentos da legislação internacional, e da parceria e cooperação para a segurança regional. Neste quadro, a participação no exercício Kwanza, permite a interoperabilidade dos sistemas militares e contribui para projetar as FAA, como nação líder neste contexto, o que ficou demonstrado segundo a opinião dos oficiais angolanos entrevistados no decorrer do exercício, realizado na região de Cabo Ledo, em Angola (Bernardino, 2013).

No contexto da SADC, a criação da Brigada em Alerta, de que Angola faz parte, desde 17 de agosto de 2007, durante a Cimeira de Chefes de Estado e de Governo da SADC, em Lusaka, tem registado significativos progressos quanto à organização e participação dos Estados-membro em exercícios no contexto das operações de manutenção de paz. A SADCBRIG tem como objetivo principal realizar missões de observação e controle, intervenção num Estado membro ${ }^{5}$ e realizar, entre outras, missões de desarmamento e desmobilização pós-conflito. Esta Brigada é integrada por cerca de seis mil efetivos da SADC, entre militares e policias, incluindo também membros da componente civil, residual, no intuito de partilhar a segurança no espaço subsaariano, contribuindo para o progresso, segurança e bem-estar dos cidadãos dos Estados-membro.

Nesta circunstância, a integração regional vai constituir-se, por um lado, como um instrumento de importância crucial para desenvolver e fortalecer a interdependência econômica dos países da comunidade e, assim, contribuir para promover um maior crescimento econômico e, por outro, como um dos meios para garantir a participação dos países no desenvolvimento da segurança regional. Assim, têm-se levado a efeito diversas ações formativas e de treino operacional ao nível da brigada, em que Angola tem participado ativamente, como é o caso do exercício militar Dolphin, e dos exercícios Tokghamo e Blue Angel. A brigada, integrando forças de Angola, África do Sul, Botswana, Lesotho, Malawi, Ilhas Maurício, Moçambique, Namíbia, Suazilândia, Tanzânia, Zâmbia, Zimbabué, RDC e Madagascar, está preparada para cumprir missões no quadro da UA e da ONU, no âmbito da Arquitetura de Paz e Segurança Africana. As forças de defesa e segurança estão empenhadas neste processo e, em nível regional, participam na preparação do exercício multinacional Dolphin com as forças militares dos Estados-membro da SADC.

Os exercícios MedFlag, com as Forças Armadas americanas, constituem-se em apoio das populações, com implicações na preparação dos militares e no intercambio com as organizações civis preparadas para atuar em situações de crise, conflito ou guerra - o que requer treino, organização e 
planeamento, pois que, em tempo de paz, a capacidade e a experiência de se perceber como essas organizações estão moldadas para enfrentar conflitos pode ser extremamente valioso em situações de necessidade nacional em face de catástrofes ou pandemias. Os exercícios Medflag são, assim, um passo significativo das FAA em direção ao novo papel a desempenhar na sociedade angolana nos tempos de paz e no apoio à reconstrução do país. Este exercício visa o tratamento de feridos, extinção de incêndios e busca de cadáveres, e envolve tropas especiais (comandos e fuzileiros), dentre os quais, mergulhadores da Marinha de Guerra Angolana, com equipes médicas e militares de unidades navais americanas que operam na esfera do Comando Americano para África - AFRICOM.

\section{UMA REFLEXÃO SOBRE A GEOPOLÍTICA DA SEGURANÇA NA REGIÃO DO GOLFO DA GUINÉ}

Nos anos mais recentes, os recursos energéticos estratégicos têm ganho uma maior proeminência no contexto geoestratégico energético internacional, nomeadamente, devido ao fato do petróleo e do gás natural desempenharem um papel relevante no quadro da balança energética global. A sua utilização, tendo em conta a limitada disponibilidade destes recursos não renováveis, está a criar novas dinâmicas nas relações internacionais e conduziu, segundo Roland Pourtier (2011), a uma reavaliação das estratégias energéticas tanto nos países produtores, como nos países consumidores, com repercussão muito específica nas dinâmicas político-estratégicas na África.

No contexto, a região do Golfo da Guiné, que cobre o espaço entre o Benim e a Guiné Equatorial, constitui uma vasta região petrolífera, integrando países produtores de petróleo como: Angola, Camarões, Gabão, Guiné Equatorial, Nigéria, RDC, República do Congo e São Tomé e Príncipe, o que levou à criação de uma organização que interligasse estas dinâmicas e estes interesses, tendo sido criada, para o efeito, a Comissão do Golfo da Guiné (CGG) ${ }^{6}$. Assim, esta região emergiu como potência global produtora de hidrocarbonetos e tem levado à definição de um novo realinhamento político-estratégico regional, pelo fato de configurar uma importante fonte alternativa de abastecimento de hidrocarbonetos aos principais mercados mundiais, acrescentando ao fato, entre outras características, a excelência em termos da qualidade do petróleo produzido (baixo teor de enxofre) e porque o seu escoamento é praticamente todo feito em mar aberto, relevan- 
do-se economicamente mais viável e apetecível (Carvalho, 2011).

A importância geoestratégica da região, não só em matéria de produção e exploração dos hidrocarbonetos, deve ser vista num contexto mais alargado, onde o interesse das potências globais, com o objetivo de garantir o controle das principais regiões de abastecimento de petróleo e gás natural na região, numa área que engloba o Atlântico Sul com um perigoso vazio estratégico e tem uma larga via de acesso e escoamento, mas, também, com preocupações securitárias acrescidas ao nível da segurança marítima.

África e os países africanos, nomeadamente Angola, tornaram-se uma nova área de interesse geoestratégico, muito pela produção de petróleo da região do Golfo da Guiné, visto como um complemento, ou mesmo a substituição, do fornecimento global que advinha da região do Golfo Pérsico. Ao mesmo tempo, a administração americana desenvolve estratégias de segurança para controlar os espaços vazios, tais como o Sahel (a sul), evitando que sejam locais para mobilização e treino de organizações terroristas globais.

Neste cenário, constata-se que as forças militares dos países da região dificilmente poderão garantir um controle eficaz sobre as suas águas territoriais, com evidentes reflexos negativos ao nível da economia, da soberania e colocando em risco a segurança nacional e regional, principalmente pela violação das fronteiras marítimas - deficientemente definidas nesta região -, que, muitas vezes, são alvo da exploração ilegal e uso abusivo dos seus recursos. Além disso, a inadequada estratégia milita, onde ressalta a falta de acordos sobre a segurança marítima regional, não fornece a segurança necessária para o Estado e para a proteção dos seus bens. Consequência imediata é o aumento da insegurança e a necessidade de se criarem mecanismos regionais que garantam a segurança das populações e dos interesses dos Estados, pois que, para ameaças mais complexas e em áreas geográficas maiores, estes não têm meios militares para as neutralizar (Metogo, 2006).

Militarmente, a construção de uma aliança regional parece ser a meta, onde os países deverão procurar aumentar as medidas de reforma, incluindo o estabelecimento de alianças na área, lutando contra o terrorismo e mantendo a paz ,o que continuará a ser o foco primário dos instrumentos militares na APSA, cenários em que as FAA estão já a participar, mas que implica um maior investimento na segurança marítima e na partilha de vigilância, informações e operacionalização combinada de mecanismos de resposta rápida regional, essencialmente com uma componente naval mais robusta. 


\section{CONSIDERAÇÕES FINAIS}

A República de Angola desenvolve no quadro regional de ação uma política externa ativa e envolvente, em que parte das suas estratégias estão ligadas às atividades realizadas pelas Forças Armadas Angolanas no quadro da SADC e da ECCAS, refletindo uma postura estratégica que está associada às prioridades de Angola no âmbito das suas aspirações a potência regional em ascensão na África Subsaariana.

Neste quadro político-estratégico de afirmação regional, o papel das FAA na defesa da sua soberania, principalmente as questões das fronteiras e da segurança marítima, que constitui uma preocupação constante do Executivo angolano, implica um crescente envolvimento na APSA e nas estruturas regionais de segurança. Este aspecto potencia as Forças Armadas como elementos da política externa regional e como atores da segurança e da defesa dos interesses de Angola na região e no continente, que se coloca como forma de influência político-diplomática na região.

As Forças Armadas Angolanas preparam-se para, no futuro, serem mais profissionais, mais intervencionistas e mais operacionais no contexto regional subsaariano, constituindo um instrumento ativo da política externa do Estado angolano, contribuindo, assim, em nossa opinião, para a afirmação da República de Angola no quadro da UA, SADC e ECCAS, na região subsaariana e na África; isso num quadro geopolítico e geoestratégico inovador, em que Angola assume o estatuto de membro-não permanente do Conselho de Segurança das Nações Unidas, constituindo fator de afirmação de Angola como produtor de segurança regional, continental e global. 
RBED, v. 2, no 1, jan./jun. 2015

\section{NOTAS}

1. Forças Armadas Populares de Libertação de Angola - FAPLA e as Forças Armadas de Libertação de Angola - FALA.

2. Designado por Continental Early Warning Sistem (CEWS).

3. Para já, apenas terrestre e aérea.

4. Como é propósito da UA criar uma força militar em estado de alerta permanente, isto é, uma força que esteja em condições de, num tempo adequado, poder pré-posicionar-se para o emprego em qualquer dos cenários de crise previstos, o que só é possível com Forças Armadas que tenham um elevado grau de preparação e prontidão operacional e que se preparem (treinem) para esta tipologia de cenários e de missões. O Documento Quadro da Edificação da FAeA mostra-nos que as componentes militar, policial e civil deverão ser autossustentadas durante a fase inicial das operações, e com capacidades para garantir o cumprimento da missão até que os canais logísticos estejam estabelecidos, e, ainda, assegurados os fornecimentos por parte da ONU/UA ou por intermédio de uma nação líder no apoio logístico. O nível de autonomia logística significa que, quando as tropas se instalarem, deverão ser independentes de qualquer apoio externo por um período mínimo de 30 a 50 dias, implicando que os países que contribuem com forças devem estar preparados para sustentar as suas unidades com recursos próprios, desde o momento da entrada na área de operações até que o sistema logístico seja estabelecido pela nação quadro (ou organização) responsável pelo apoio logístico.

5. De modo a restaurar a paz e segurança, ou a prevenir uma crise ou conflito regional, impedindo que se agrave ou alastre para áreas ou Estados vizinhos. 
O NOVO PARADIGMA DA SEGURANÇA NA ÁFRICA: A ESTRATÉGIA SECURITÁRIA REGIONAL ANGOLANA

\section{RESUMO}

A participação da República de Angola na Arquitetura de Paz e Segurança Africana representa, no atual contexto subsaariano, o exemplo da procura de afirmação de uma potência regional em ascensão, que através de uma Política Externa participativa, influente e de compromisso, aposta numa dualidade estratégica de equilíbrio, em que as Forças Armadas Angolanas são empregues como instrumento de cooperação militar regional e de resolução de conflitos no seu espaço de interesse conjuntural, num quadro geopolítico em que a república de Angola se constitui como membro não permanente do Conselho de Segurança das Nações Unidas.

Palavras-chave: Angola, Arquitetura de Paz e Segurança Africana, Segurança e Defesa, Forças Armadas Angolanas.

\section{ABSTRACT}

The participation of the Republic of Angola in the African Peace and Security Architecture represents, in the current sub-Saharan context, the example of a search for strategic affirmation of a rising regional power, through a participatory, influential foreign policy and commitment, bet at strategic balance duality in which the Angolan Armed Forces are an instrument of military cooperation and conflict resolution in Angolan's conjectural interest space in a context about to be non-permanent member of the Security Council in the United Nations.

Keywords: Angola, African Peace and Security Architecture Security and Defense, Angolan Armed Forces.

\section{REFERÊNCIAS}

Almeida, Eugénio da Costa. (2011) Angola. Potência Regional em Emergência. Lisboa: Edições Colibri.

Angola. (2010) Constituição Federal da República de Angola. Luanda, 2010. Disponível em: http://www.governo.gov.ao/Arquivos/Constituicao_da_Republica_de_ Angola.pdf.

Barros, Manuel Correia de (Coord). (2006) Reflexões sobre Geopolítica e Geoestratégia 
RBED, v. 2, no 1 , jan./jun. 2015

em Angola e em África. Luanda: Editorial Nzila, Centro de Estudos Estratégicos de Angola, $1^{\text {a }}$ Edição.

Bernardino, Luís Manuel Brás. (2008) Estratégias de Intervenção em África. Uma década de Segurança e Defesa na Comunidade dos Países de Língua Portuguesa. Lisboa: Editora Prefácio.

(2013), A posição e Angola na Arquitectura de Paz e Segurança Africana. Análise da Função Estratégica das Forças Armadas Angolanas. Coimbra: Editora Almedina.

Carvalho, António Manuel Luvualu de. (2011) Angola. Economia e Petróleo (20022010). Lisboa: Universidade Lusíada Editora.

Cillier, Jakkie. (2005) "Toward a Continental Early warning System for Africa". Occasional Paper, No. 102. South African Foreign Policy and African Drivers Programme. South African Institute of International Affairs (SAIIA). Disponível em: http: //www.iss.co.za/Pub/papers/102/Paper 102.html.

James III, W. Martin. (2011) A Political History of the Civil War in Angola 19741990. New Jersey: Transaction Publishers.

Júnior, , Miguel. (2003) A Formação e o Desenvolvimento das Forças Armadas Angolanas. Luanda: Editorial Nzila.

Leão, Ana; Rupiya, Martin. (2005) "A Military History of the Angolan Armed Forces from the 1960's Onwards - As Told by Former Combatants." In: Rupiya, Martin. Evolutions $\mathcal{E}^{2}$ Revolutions - A Contemporary History of Militaries in Southern Africa. South Africa, International Security Studies (ISS). Disponivel em: http:// www.isn.ethz.ch/isn/Digital-Library/Publications/Detail/?ots591=0c54e3b31e9c-be 1e-2c24-a6a8c7060233\&lng=en\&id=108507.

Malaquias, Assis. (2011) "Angola's Foreign Policy: Pragmatic Recalibrations." Occasional Paper No. 84. South African Foreign Policy and African Drivers Programme. South African Institute of International Affairs (SAIIA), May 2011. Disponivel em: http://www.saiia.org.za/occasional-papers/angolas-foreign-policy-pragmatic-recalibrations

Messiant, Christine. (2008) L'Angola postcolonial - 1. Guerre et Paix sans Démocratisation. Paris: Éditions Karthala.

Weigert, L. Stephen. (2011) Angola: A Modern Military History, 1961-2002. London, New York: Palgrave Macmllian. 